\title{
Photomontage with Texts
}

\section{Lisa Pope}

University of California, Los Angeles

\section{Amy L. Heffernan}

University of Michigan

Ella Deloria clla veluila

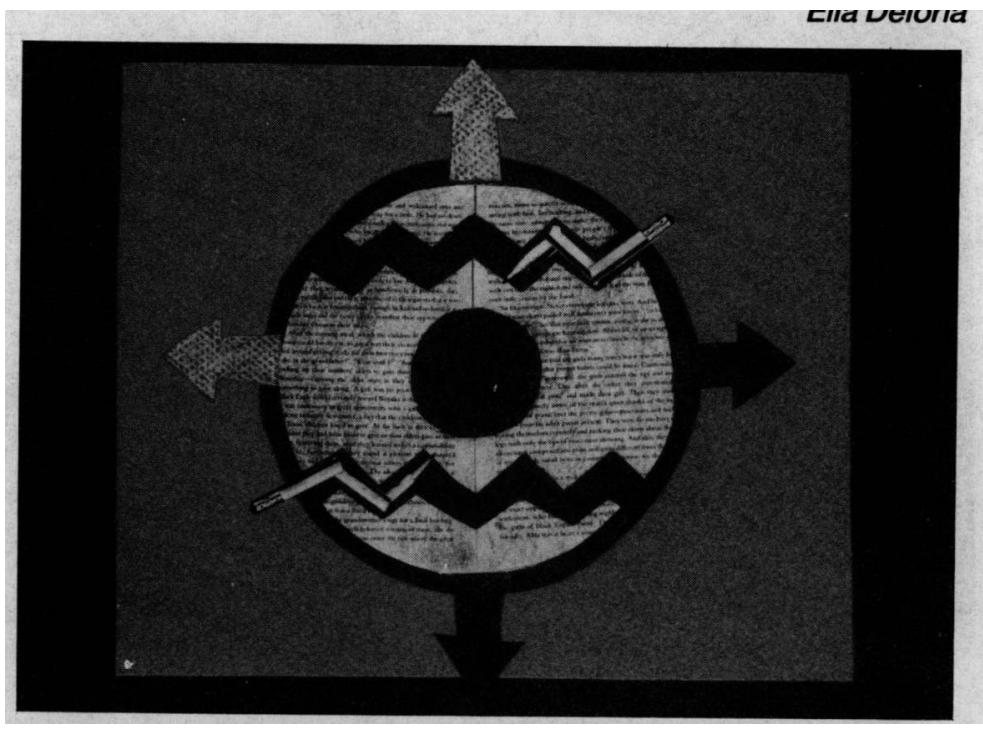

We may know a people, but we cannot truly know them until we can get within their minds, to some degree at least, and see life from their peculiar point of view. To do that we must learn what goes on in their 'spirtual cultural area'. By that fancy phrase / simply mean what remains after the tangible and visible part is cleared away. I mean such ethical values and moral principles as a people discovers to live by and that make it a group distinct from its neighbors. I mean all those unseen elements that make up the mass sentiment, disposition, and character-elements that completely blend there, producing in an integrated pattern a powerful inner force that is in habitual operation, dictating behavior and controlling the thought of all who live within its sphere.

Ella C.Deloria (1944) Speaking of Indians. Vermillion, SD: State Publishing. 


\section{Elsie Clews Parsons}

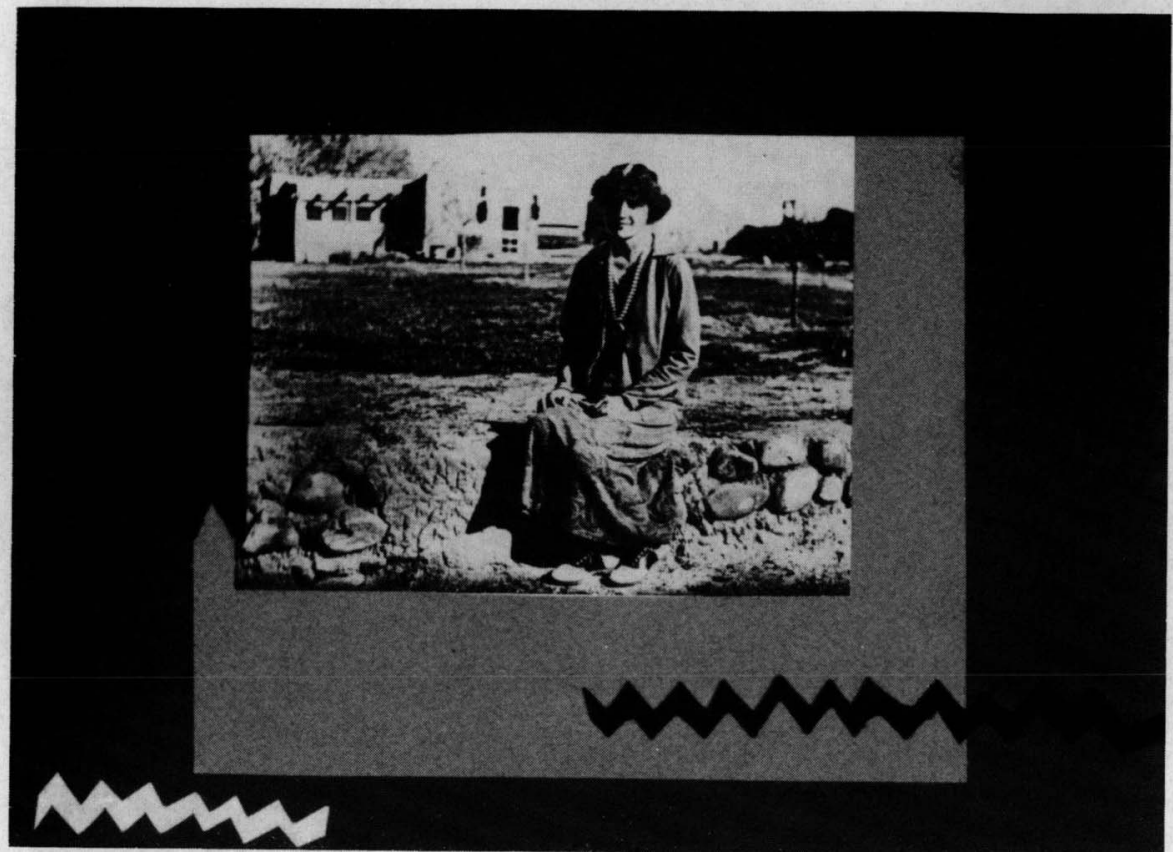

The idea of writing about the life of the Indian for the General Reader is not novel, to be sure, to anthropologists.

Appearances to the contrany, anthropologists have no wish to keep their science or any part of it esoteric. They are too well aware, for one thing, that facilities for the pursuit of anthropology are dependent more or less on popular interest, and that only too often tribal cultures have disappeared in America as elsewhere before people became interested enough in them to learn about them. . . In this book the white man's traditions about Indians have been disregarded. That the writers have not read other traditions from their own culture into the culture they are describing is less certain. Try as we may, and it must be confessed that many of us do not try very hard, few, if any of us, succeed, in describing another culture, of ridding ourselves of our own cultural bias or habits of mind.

Elsie Clews Parsons (1922) 'Preface' in American Indian Life, edited by Elsie Clews Parsons. New York: B.W. Huebsch. 
The winter is before me to acomplish anything I wish. I have difficulty only in concentrating on something . . . my pet scheme is to steep myself in the lives of restless and highly enslaved women of past generations and write a series of biographical papers from the standpoint of the 'new woman'.

My conclusion so far as I see it now is that there is nothing 'new' about the whole thing except the phraseology and the more independent economic standing of recent times - that the restlessness and groping are inherent in the nature of women and this generation can outdo the others long since past only in the frankness with which it acts upon these. . .

Ruth Benedict, 'Journal, 1912-1916', in An Anthropologist at Work: The Writings of Ruth Benedict, edited by Margaret Mead. Boston: Houghton Mifflin, 1959. Entry dated November 1914.

Ruth Benedict

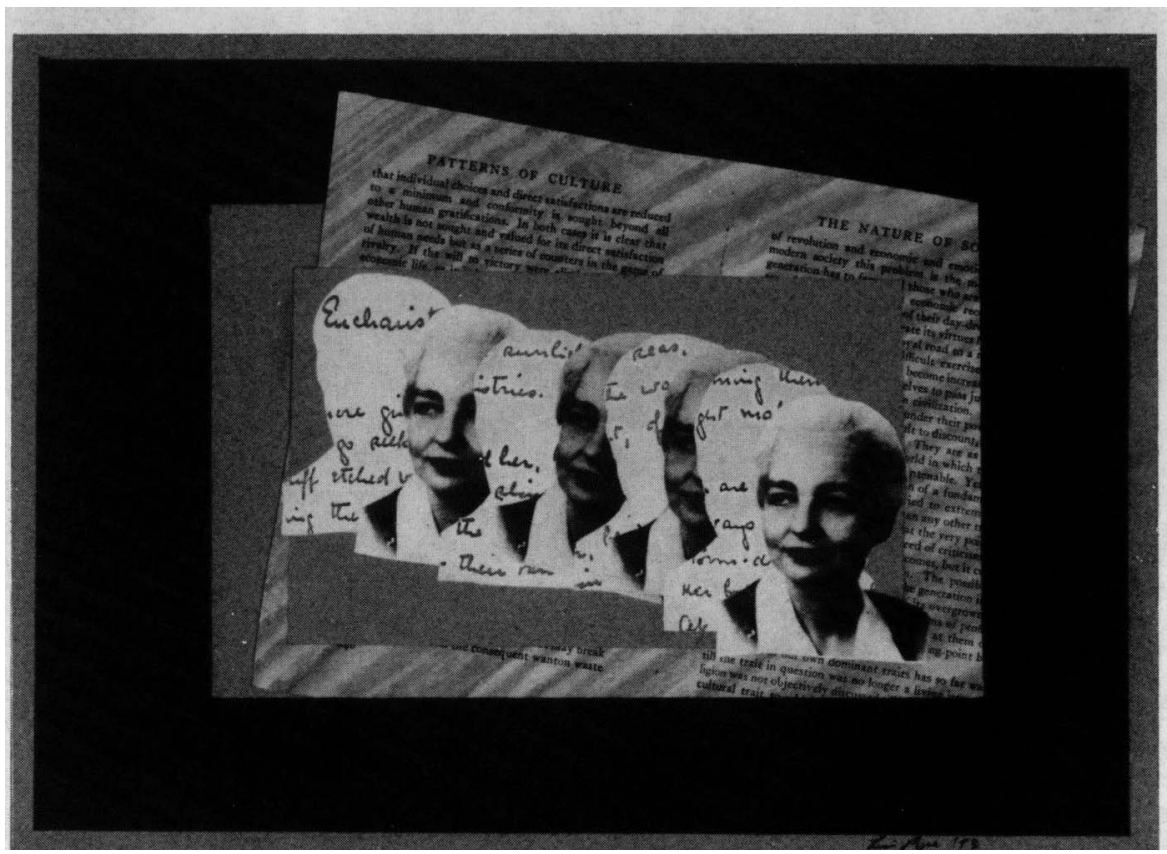


It must remain, as all anthropological works must remain, exactly as it was written, true to what / saw in Samoa and what / was able to convey of what / saw; true to the state of our knowledge of human behavior as it was in the mid1920 's; true to our hopes and fears for the future of the world. . . I can emphasize that this was the first piece of anthropological fieldwork which was written without the paraphemalia of scholarship designed to mystity the lay reader and confound one's colleagues.

Margaret Mead (1928) 'Preface' to the 1973 edition of Coming of Age in Samoa: A Psychological Study of Primitive Youth for Western Civilization. New York: Morrow Quill.

\section{Margaret Mead}

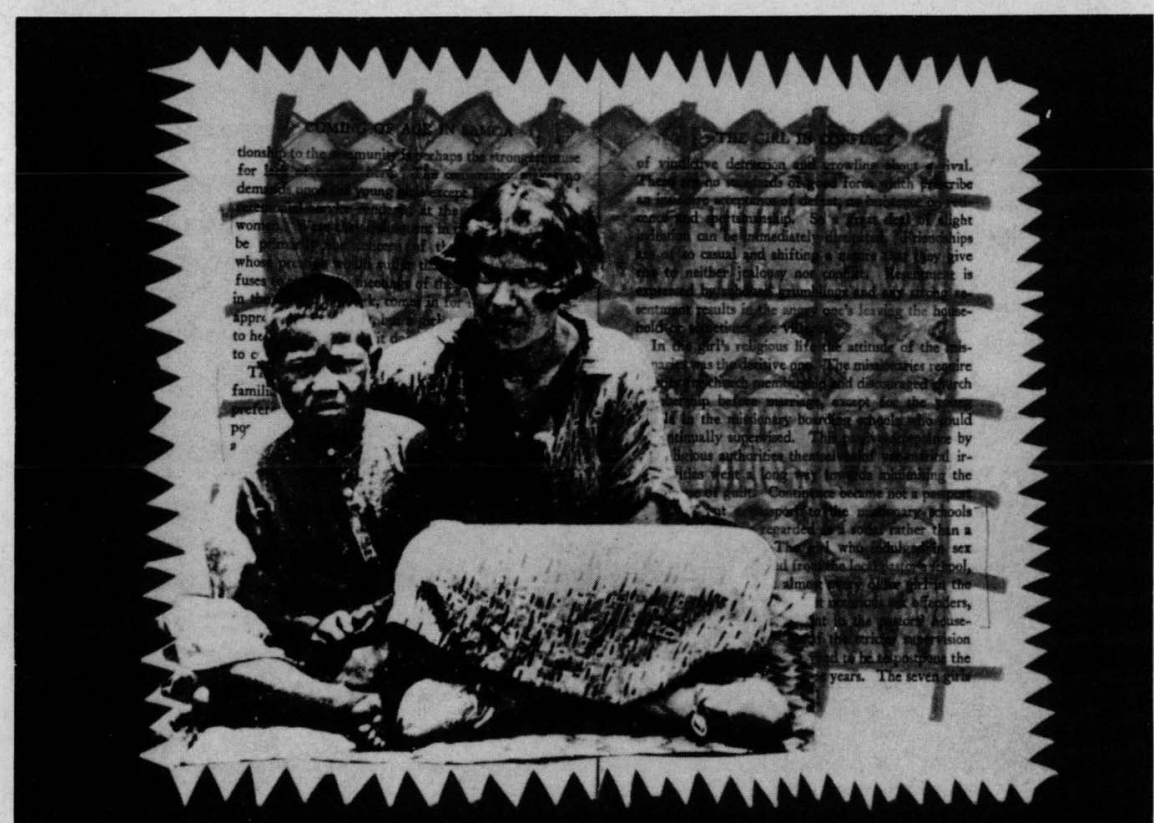




\section{Zora Neale Hurston}

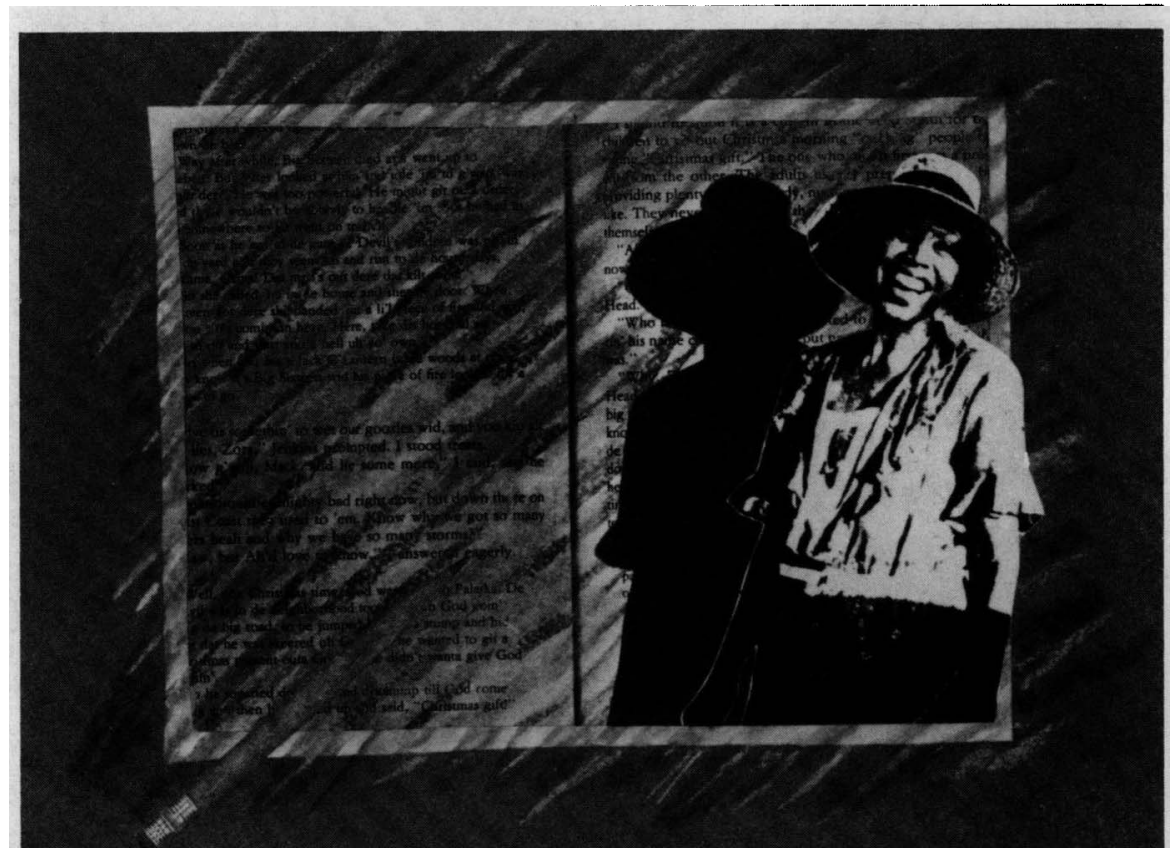

'Miss, you know uh heap uh dese hard heads wants to woof at you but dey skeered.'

'How come Mr. Pitts? Do l look like a bear or a panther?'

'Naw, but dey say youse rich and dey ain't got de nerve to open dey mouth.'

I mentally cursed the $\$ 12.75$ dress from Macy's that I had on among all the $\$ 1.98$ mail-order dresses. llooked about and noted the number of bungalow aprons and even the rolled down paper bags on the heads of several women. I did look different and resolved to fix that no later than the next morming.

'Oh, Ah ain't got doodley squat,' I countered. 'Mah man bought me dis dress de las' time he went to Jacksonville. We wuz sellin' plenty stuff den and makin' good money. Wisht $A h$ had dat money now.' Then Pitts began woofing at me and the others stood around to see how I took it.

Zora Neale Hurston (1935) Mules and Men. Philadelphia: J.B. Lippincott. (Reprinted 1970. New York: Harper and Row.) 


\section{Gladys Reichard}

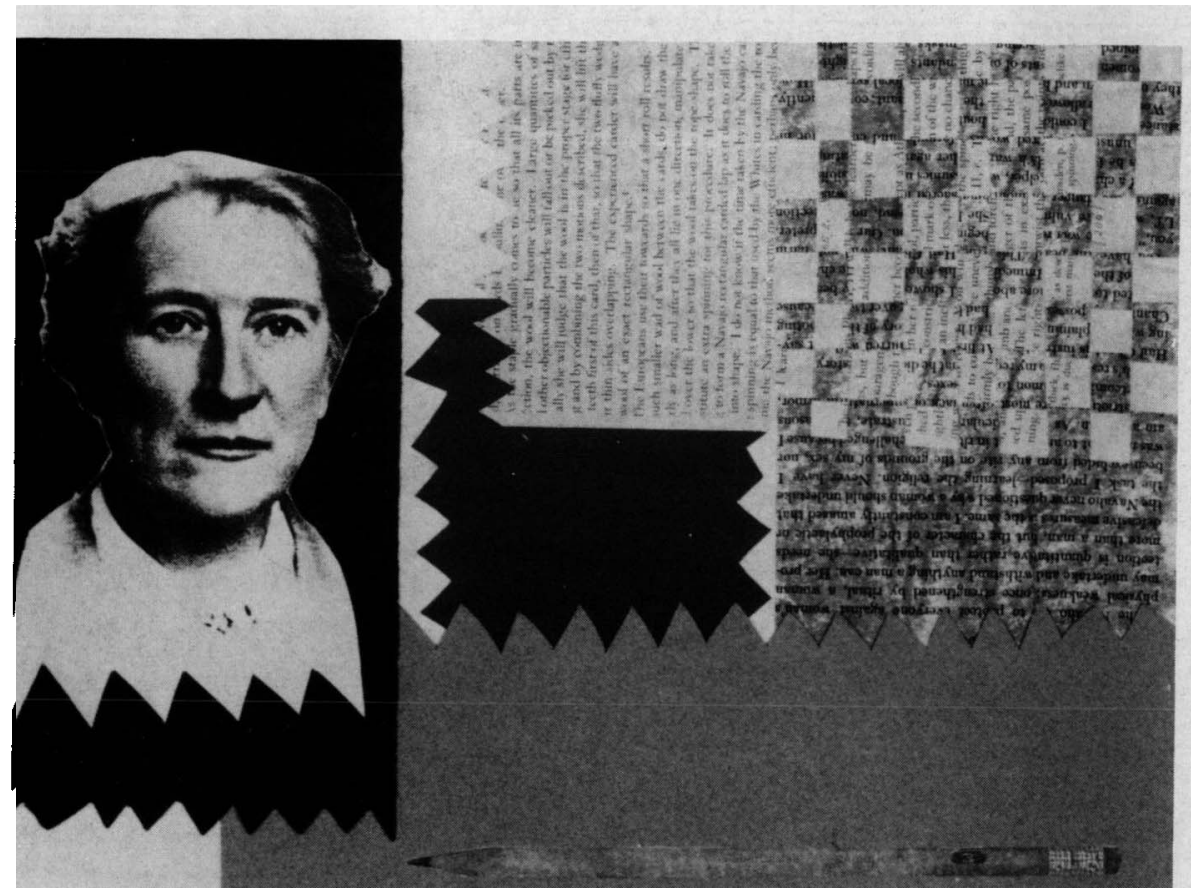

As I struggle along, learning to control unaccustomed muscles, Marie sits by my side watching carefully lest I make a mistake. We don't talk much, except about the points of the weaving. A child doesn't talk when he is learning to write. Besides, Marie does not 'tell' when teaching. She 'shows'. The Navajo word for 'teach' means 'show' and is absolutely literal. As the minutes fly, Marie winds the colors on my reeds.

Gladys A. Reichard (1934) Spider Woman: A Story of Navajo Weavers and Chanters. Glorieta, NM: Rio Grande Press. 
It is occasionally said that the major ties that exist between Eskimo spouses are those of sex and economic cooperation. Of the marriage I knew best I had a quite different impression, one compounded of a hundred small incidents: a note that Inuttiaq, storm-bound one day on the sea ice halfway to Goja Haven, wrote to Allaq and sent back with a returning dog team: 'You (his wife and daughters) who remain behind are people to be cared for (naklik)'; the quiet pleasure that I felt in Allaq's smile when she repeated to me 'He says we're to be cared for'. . . I f felt closeness in the shared eagerness with which Inuttiaq and Allaq pored over my maps together, pointing out distant lakes and rivers in whose vicinity they had hunted autumn caribou 'before we had children, ' and in their mutual amusement at the memory, years old, of the stonewalled qaqmaq that one night shed its stones onto their sleeping heads. And I felt it in the suddenness with which Inuttiaq one evening said to me, breaking a long silence with a brusque nod in Allaq's direction: 'I saw her being born.'

Jean Briggs (1970) Never in Anger: Portrait Of An Eskimo Family. Cambridge, MA: Harvard University Press.

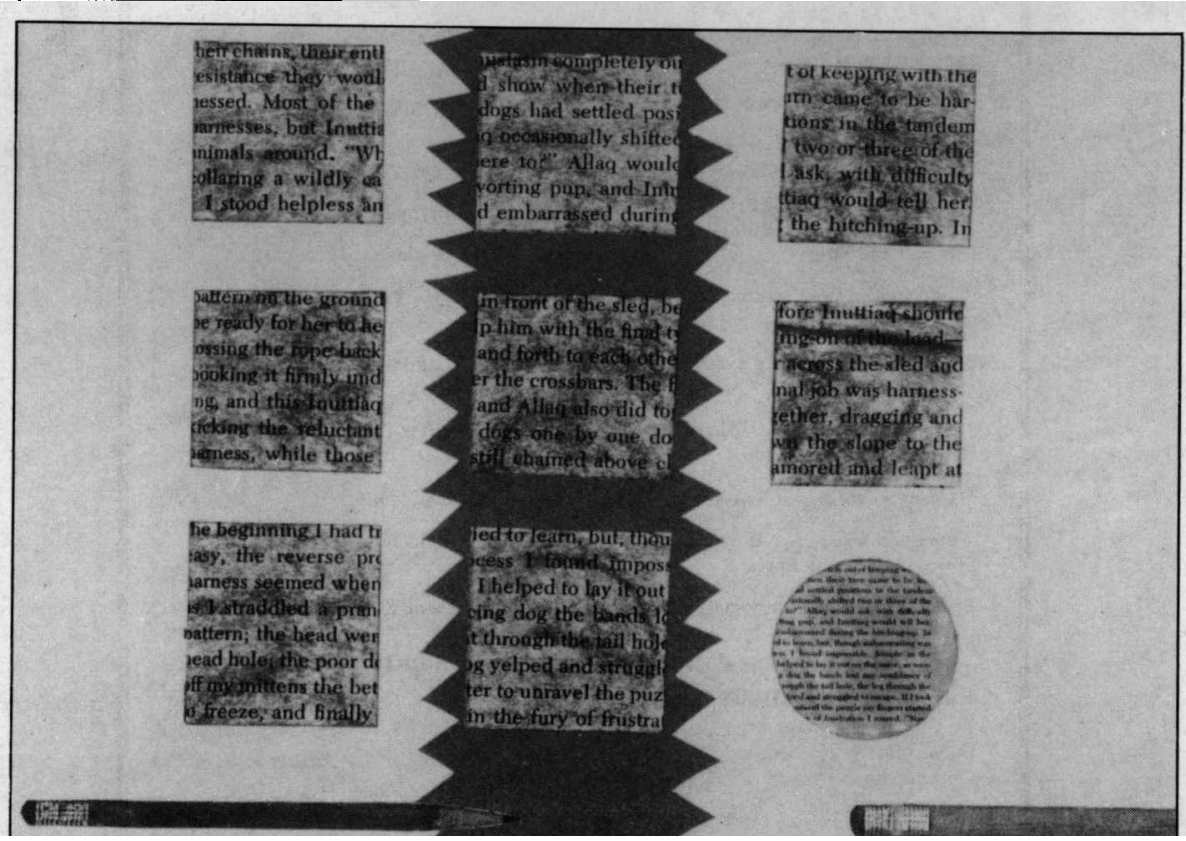

